\title{
A PRACTICAL OPTIMISATION METHOD TO IMPROVE QOS AND GOS-BASED KEY PERFORMANCE INDICATORS IN GSM NETWORK CELL CLUSTER ENVIRONMENT
}

\author{
Joseph Isabona $^{1}$ and Kingsley Obahiagbon ${ }^{2}$ \\ ${ }^{1}$ Department of Basic Sciences Benson Idahosa University, PMB.1100, Benin City, \\ Nigeria \\ ${ }^{2}$ Department of Mathematics and Computer Sciences, Idahosa University, PMB.1100, \\ Benin City, Nigeria
}

\begin{abstract}
The delivering of both good quality of service $(Q \circ S)$ and Grade of Service $(G o S)$ in any competitive mobile communication environment is a major factor to reducing subscribers' churn rate. Therefore, it is important for wireless mobile network operators to ensure stability and efficiency by delivering a consistent, reliable and high-quality end user (subscriber) satisfaction. This can only be achieve by conducting a regular network performance monitoring and optimisation as it directly impacts the quality of the offered services and hence user satisfaction. In this paper, we present the results of network performance evaluation and optimisation of a GSM network on cell cluster-basis, in Asaba region, South East Nigeria. We employ a combination of essential key performance indicators such as dropped call rate, call setup success rate and outage call rate to examine overall QoS and GoS performance of the GSM network. Our results after network optimisation showed significant performance improvement in terms of call drop rate, call set up success rate, and call block rate across. Specifically, the end user satisfaction rate has increased from $94.45 \%, 87.74 \%$, and $92.85 \%$ to $99.05 \%, 95.38 \%$ and $99.03 \%$ respectively across the three GSM cell clusters. The GoS is reduced from 3.33\%, 6.60\% and $2.38 \%$ to $0.00 \%, 3.70 \%$ and $0.00 \%$ respectively. Furthermore, ESA, which correspond end points service availability, has improved from $94.44 \%, 93.40 \%$ and $97.62 \%$ to $100 \%, 96.30 \%$ and $100 \%$ respectively. In addition, the average throughput has improved from $73.74 \mathrm{kbits} / \mathrm{s}, 85.06 \mathrm{kbits} / \mathrm{s}$ and $87.54 \mathrm{kbits} / \mathrm{s}$ to $77.07 \mathrm{kbits} / \mathrm{s}, 92.38 \mathrm{kbits} / \mathrm{s}$ and $102 \mathrm{kbits} / \mathrm{s}$ respectively across the three GSM cell clusters.
\end{abstract}

\section{KEY WORDS}

Quality of Service, Grade of Service, Network Optimisation, End user Satisfaction

\section{INTRODUCTION}

In recent time, mobile telephony has become one of the fastest growing and most demanding telecommunications applications especially since the introduction of the second generation $(2 \mathrm{G})$ based Global System for Mobile communications (GSM) [1]. The GSM group was founded in 1982 and till today, it remains one of the leading mobile communication systems with over a billion end users and a market share of $70 \%$ [2]. However, this has not also be without the provision of good service quality changes. Therefore, to maintain the above growth and retain existing customers, as well as attracting new ones, the GSM service providers need to deliver its' services, consistently, reliably and economically, as the customer satisfaction on the service is 
directly dependent on the quality and the performance of the network. More importantly, mobile telephony service providers must be ready to continue to maintain the highest quality of service (QoS) to both residential and industrial subscribers. Therefore, once a radio telephone network is designed and operational, its performance should be monitored to improve overall service quality. That is where network performance monitoring for QoS assessment, analysis of faults and corrective actions comes in. In addition to monitoring network faults, the operator also needs immediate information on how the network performs, especially from the end user perspective. The end user network performance report can be used as source of information for corrective actions or for evaluating the utilization of resources. This in turn enables the mobile telephone operators to optimize traffic and investigate critical areas where the network performance could require adequate changes. Also, network optimization engineers should make effort on regular basis to improve the service quality and capacity of operational networks, as well as developing and deploying new ones in order to meet customer demands. Moreover, carrying out regular optimization remain essentially the only way to keep track of the network by looking deep into network operation statistics and collecting/analyzing drive test data.

\section{Problem Statement}

In recent times, it has been observed that not all the telecom operators are giving due attention to the quality of service (QoS) in Nigeria. Service quality of some mobile telephone networks instead of being improved has been following a deteriorating trend (e.g. see our previous work in [3]). With the increase of the subscriber base, customers' complain has also increased. Today, some of the common issues being faced by the subscribers are recurrent call drop, poor network coverage and unsatisfactory customer care support. As a result, customer's dissatisfaction is increasing and complains against the network are also increasing, which in turn leads to low customers loyalty and high churn rate. In some cases, operators are implementing new features in their networks without performing proper pre-trial which is also a reason for poor QoS.

Consequently, how to carry out a proper network optimization to resolve the above mentioned problems and improve the end users satisfaction rate with the good quality and grade of service (GoS) is the real challenge.

\section{Research Methodology}

Generally, network optimization can be seen as a very involving process as a large number of variable are available for tuning impacting different aspect of the network performance. The process involves the use of various methods to maximize the system performance by optimally configuring the network and utilizing its resources. To simplify this process, a step by step method is required. In this study, the following methods are adopted to achieve our goal:

1. Single site verification exercise

2. Pre Swap Drive Test

3. $\log$-file analysis

4. Implementation of recommendation proffered for optimization

5. Post Swap Drive Test

6. Post Swap Drive Test Report and Analysis

In the first place, Single site verification exercise enables one to verify the status of the base stations within the cluster to be optimized. Here, the individual sites are verified to make sure they are free of critical hardware problems before the optimization process is kick off. Also, in this exercise, some key engineering parameters like antenna height, antenna tilt, transmit power, 
among others, are properly checked in each of the cell sites for errors and inconsistency with that in the site data obtained before the optimization exercise.

This is followed by collecting and analyzing data from Pre Swap Drive Test carried out on the selected routes and also data from networks nodes by using customized software.

After collection, the log-file is analyzed to identify possible problems within the networks. This is done to improve the network performance.

Implementation of recommendation involves tuning the engineering antenna parameters such as the antenna tilt, and parameter auditing.

This followed by carrying out another drive test ( i.e Post swap drive test) exercise to ascertain the effect of the changes in the network parameters. The Post Swap drive test report will include the same reports as the Pre Swap Drive Test.

After each optimization exercise, the Key Performance Indicators (KPIs) obtained are analyse and checked against the desired threshold. See figure 1 for a summary of network optimization process.

In this paper, we specifically engaged a combination of essential KPIS such as dropped call rate, call setup success rate and outage call rate to examine overall QoS and GoS performance of the investigated GSM network. This in turn allowed us to determine the end user satisfaction rate and the general network performance. This exercise took place after some key problems such as poor transmission line performance, reduced power output, cell coverage degradation, coverage hole, over shooting, cell imbalance, poorly connected feeders, Increased interference and among others were identified across the studied GSM cell clusters, the following recommendations were made and implemented on the network to optimise its performances:

- Addition of missing adjacent cells in each cell cluster

- antenna azimuth and tilt changes

- BTS Equipment/Filter change

- Re-tuning of interfered frequencies

- Adjustment accessibility parameters

- power parameters changes

- Increase the reuse distance between the co-frequency and adjacent frequencies.

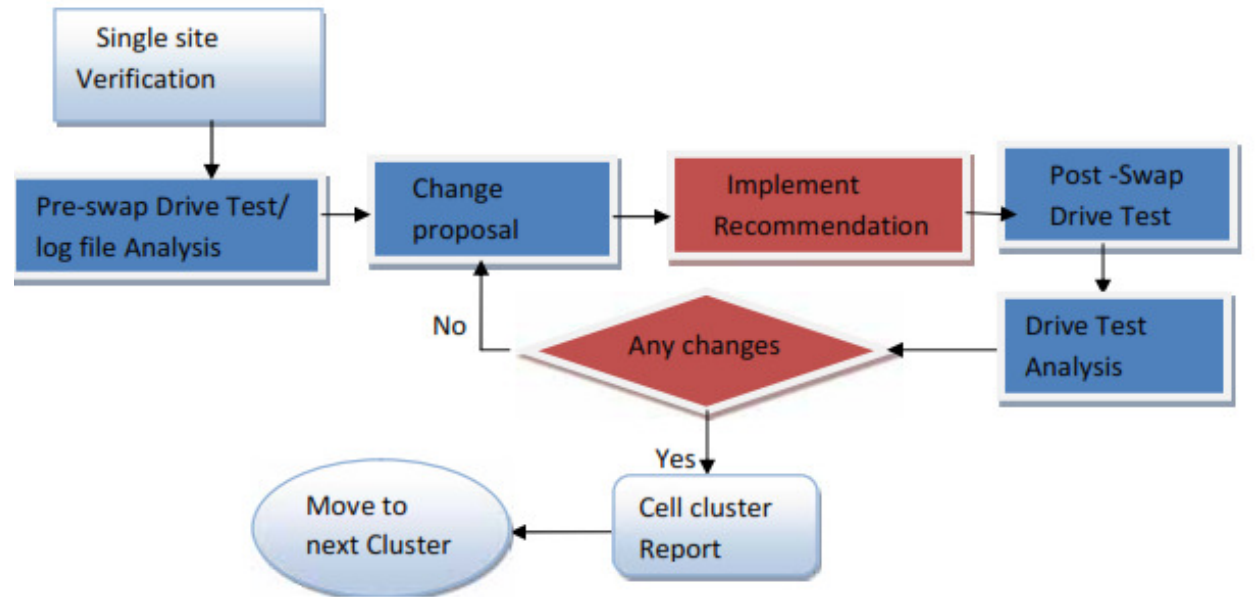


Figure 1: Network Optimization flowchart.

\section{The Investigated Environments}

This study was carried out with the need to enhanced end user satisfaction as desired by one of the leading cellular network service providers in South East, Nigeria. The operator recently engaged one of the equipment vendors in the country for BTS swapping across so some selected cities in Asaba Area, South East Nigeria. To carry out the swap drive test experiment, the study area was divided into three clusters. Each cluster has 26-40 sites on Air.

In order to find swapped feeders, a test was performed by driving round the cell sites to secure that the planned physical cells' identities are in order. The lists of the sites ID are given in table 13.

\section{Performance Measures}

In telecommunication engineering, and in particular teletraffic engineering, the quality of voice service is specified by two measures (Jang-Sub et al, 2008) [4]: the Grade of Service (GoS) and the Quality of Service (QoS). In the ITU-T Recommendation E.800 [5], QoS is defined as the collective effect of service performance, which determines the degree of satisfaction of a user of the service. How the end-user perceives the service quality, i.e. his satisfaction with the service as a function of the measured parameters, is highly dependent on the service level (QoSparameters) he is accustomed to. QoS is a measure of the Key Performance Indicators (KPIs).

$\mathrm{GoS}$ is a subset of QoS and it is the mechanism for controlling the performance, reliability and usability of a telecommunications service. The smaller the value of GoS, the better is the service. A telephone service is available if the GoS is better than a specified percentage. Availability is the QoS characteristic that represents the proportion of time when satisfactory service is available.

\section{QoS-Based Key Performance Indicators (KPIs)}

According to ETSI's standards [6] QoS KPIs can be categorized in five phases during service use from the customer's point of view:

1. Network Availability: The probability that a service is available when the end user requires it, is called availability.

2. Network Accessibility: Probability that the user performs a successful registration on the network.

3. Service Accessibility: Accessibility has to do with the end users being able to set up a call and access radio resources. If the user wants to use a service, the network operator should provide him as fast as possible access to the service. Includes KIP's that describe how successful is the service access (e.g, call setup rate) as well as KPI's that describe setup time (i.e, call setup time).

4. Service Integrity: This describes the QoS during service use. Includes KPI's that describe the quality of the service.

5. Service Retainability: Retainability covers the ability to keep up a call; either in accordance with or against the will of the user. It Includes KPI's that count the time that a service can retain (Drop Call Rate or call holding time).

The service quality performance indicators we will consider in this paper cover the different phases of QoS [6] aspects during service use from the customer's point of view. They are here defined by: 
- Call Setup success rate (CSSR): The measure of the service accessibility provided by GSM network is the call set-up rate (CSSR). This indicator measures the ease in which calls are established or set up. It analyses the ability to successfully establish voice communications between two ends, a mobile network terminal and a fixed network terminal, and the ability of networks to maintain this call during a pre-established period of time. Mathematically, CSSR describes the ratio between the calls successfully connected to the system and the overall number of call attempts:

$$
\text { CSSR }=\frac{\text { Nattempt }- \text { Nblock }}{\text { Nattempt }}
$$

where Nattempt is the number of call attempts and Nblock is the number of blocked calls.

- Drop Call rate (DCR): The measure of the service retainability, which describes the termination of services in accordance with or against the will of the end user is the CDR. It is defined by the ratio between the number of dropped calls and the overall number of call releases:

$$
\mathrm{CSSR}=\frac{\text { Ndrop }}{\text { Nrelease }}
$$

where Ndrop is the number of dropped calls and Nrelease is the overall number of call releases.

- Outage rate (OutR): This indicator measures service integrity, which is the QoS during service use. OutR describes the ratio between the number of calls which, although normally released, perceived an unacceptable outage time lasting more than $5 \%$ of the duration of the call, and the overall number of call releases (that is both the normal and the abnormal releases) [7]:

$$
\text { OutR }=\frac{\text { Nout }}{\text { Nrelease }}
$$

where Noutage is the number of calls with unacceptable outage time.

- End points Service Availability (ESA): This indicator measures service availability, which is the QoS during service use and it is appraise from the view point of what the customer get from their end. Endpoints are defined as the interface between the customer and the equipment providing access to the service. ESA is defined as the percentage of time a usable call can be established and maintained between two end points. The measurement of ESA is described by the ratio:

$$
\mathrm{ESA}=\frac{\text { Nattempt }- \text { Nblock-Ndrop }}{\text { Nattempt }}
$$

- Satisfaction rate (SatR): it summarises the degree of voice user satisfaction, by considering altogether service accessibility, service retainability and service integrity. A call is considered satisfied if it isn't blocked, nor dropped, nor it didn't feel outage [7]:

$$
\begin{aligned}
\text { SatR } & =[\text { CSSR }(1-(D C R+\text { OutR })] \\
& =\frac{\text { Nattempt }- \text { Nblock-Ndrop }}{\text { Nattempt }} \times \frac{\text { Nrelease-(Ndrop-Nout })}{\text { Nrelease }} \\
& =\frac{\text { Nattempt-Nblock }}{\text { Nattempt }} \times \frac{\text { Nsat }}{\text { Nrelease }}
\end{aligned}
$$

where Nsat is the number of satisfied users, that is the calls which were successfully connected to the network and were normally released without perceiving significant outage during the call. 


\section{GoS-Based Key performance Indicators (KPIs)}

In GSM networks handle both voice and data traffic requirements of the mobile communication by providing two modes of operation:

- Circuit switched (which caters for voice based traffic) or

- Packet switched (which caters for data traffic)

Circuit switching provides the customer with a dedicated channel all the way to the destination. For circuit switch services in GSM, blocking probability can be successively used as a performance indicator for the evaluation of GoS. It expressed by the formula:

$$
\text { GoS (blocking probability) }=\frac{\text { Nattempt }- \text { Nrelease }}{\text { Nattempt }}
$$

The above expression provides a measure of the ability of a user to access the system during the busiest hour which is specified as the probability of a call being blocked.

Here, the GoS for packet switch services is expressed in terms of throughput which represents the long-run throughput per service. The throughput is derived by considering the long-run rate at which the user enters the air interface and the data rate per user by employing the following formula [8]:

$$
\text { Throughput }=\mathrm{R} \lambda(1-\text { blocking probability })
$$

where

$\mathrm{R}$, is the data rate of service blocking probability and the call arrival rate, $\lambda$, refers to the traffic offered expressed as the number of call attempts per unit time which is given by [9], [10]:

$$
\lambda=\frac{\text { Nattempt }}{\text { Unit time }}
$$

With packet switching, the operator assigns one or more dedicated channels specifically for shared use. These channels are up and running 24 hours a day, and when you need to transfer data, you access a channel and transmit your data. The standard data rate of a GSM channel is $22.8 \mathrm{kbps}$.

\section{RESULTS AND DISCUSSION}

Tables 1-3 and figures 2-4 shows the network performances at studied three cell cluster environments using the basic KPIs. It can be clearly seen from the tables that performance of the network before and after optimisation showed significant performance improvement in terms of call drop rate, call set up success rate, and call block rate.

Figures $6 \mathrm{a}$ and $6 \mathrm{~b}$ show the radar and the bar plots of end user satisfaction rate performance at various GSM cell clusters. The distribution of end user satisfaction rate before optimisation shows an increased in performance from $94.45 \%, 87.74 \%$, and $92.85 \%$ to $99.05 \%, 95.38 \%$ and $99.03 \%$ respectively after optimisation across the three GSM cell clusters. In addition, the GoS as shown in the plots of figure 8 is reduced from $3.33 \%, 6.60 \%$ and $2.38 \%$ to $0.00 \%, 3.70 \%$ and $0.00 \%$ before and after optimisation respectively. Furthermore, in figure 7, ESA performance, which correspond end points service availability, has improved from $94.44 \%, 93.40 \%$ and $97.62 \%$ to $100 \%, 96.30 \%$ and $100 \%$ before and after optimisation respectively. Also, the average throughput has improved from $73.74 \mathrm{kbits} / \mathrm{s}, 85.06 \mathrm{kbits} / \mathrm{s}$ and $87.54 \mathrm{kbits} / \mathrm{s}$ to $77.07 \mathrm{kbits} / \mathrm{s}, 92.38 \mathrm{kbits} / \mathrm{s}$ and 
$102 \mathrm{kbits} / \mathrm{s}$ respectively across the three GSM cell clusters as showed in figures $9-11$ before and after optimisation across the investigated GSM cell clusters.

\begin{tabular}{|l|l|l|}
\hline Cluster ID: & CLUSTER 1 \\
\hline Indicators & Swap Before & Swap After \\
\hline \% Blocked calls & 3.33 & 0.00 \\
\hline \% Dropped calls & 2.30 & 0.95 \\
\hline \% Established calls & 96.67 & 100 \\
\hline \% Good calls & 97.70 & 99.50 \\
\hline \% Call Set-up Success & 96.67 & 100.0 \\
\hline Outage calls & 0.00 & 0.00 \\
\hline $\begin{array}{l}\text { Average } \\
\text { Throughput(kbits/s) }\end{array}$ & 73.74 & 77.06 \\
\hline
\end{tabular}

Table 1: $1^{\text {st }}$ Cell Cluster, Unoruka Road, Akwa Etiti and environs.

Table 2: $2^{\text {nd }}$ Cell Cluster, Awada Onitsha and environs

\begin{tabular}{|l|l|l|}
\hline Cluster ID: & CLUSTER 2 \\
\hline Indicators & Swap Before & Swap After \\
\hline \% Blocked calls & 6.60 & 3.70 \\
\hline \% Dropped calls & 6.06 & 0.96 \\
\hline \% Established calls & 93.40 & 96.30 \\
\hline \% Good calls & 93.94 & 99.04 \\
\hline \% Call Set-up Success & 93.40 & 96.30 \\
\hline Outage calls & 0.00 & 0.00 \\
\hline $\begin{array}{l}\text { Average } \\
\text { Throughput(kbits/s) }\end{array}$ & 85.06 & 92.38 \\
\hline
\end{tabular}

Table 3: $3^{\text {rd }}$ Cell Cluster, Palobis Place Onitsha and environs

\begin{tabular}{|l|l|l|}
\hline Cluster ID: & CLUSTER 3 \\
\hline Indicators & Swap Before & Swap After \\
\hline \% Blocked calls & 2.38 & 0.00 \\
\hline \% Dropped calls & 4.88 & 0.97 \\
\hline \% Established calls & 97.62 & 100 \\
\hline \% Good calls & 95.12 & 99.02 \\
\hline \% Call Set-up Success & 97.62 & 100 \\
\hline Outage calls & 0.00 & 0.00 \\
\hline $\begin{array}{l}\text { Average } \\
\text { Throughput(kbits/s) }\end{array}$ & 87.54 & 102.65 \\
\hline
\end{tabular}


International Journal of Wireless \& Mobile Networks (IJWMN) Vol. 6, No. 5, October 2014

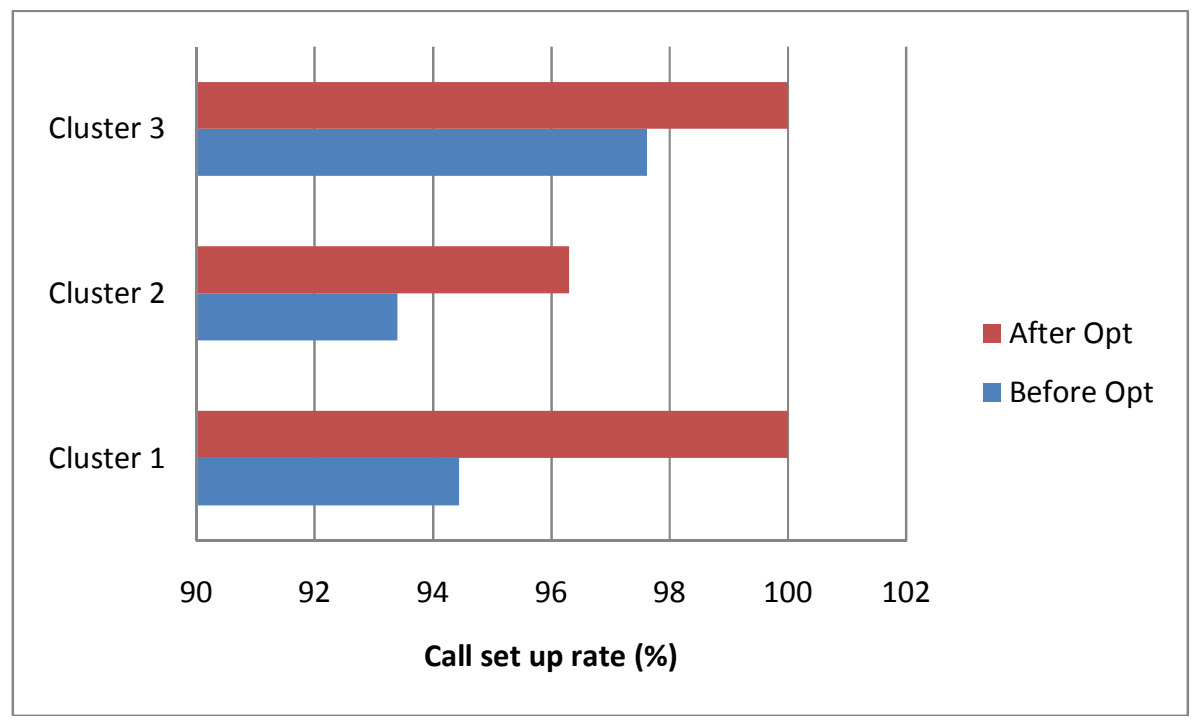

Figure 2: CSSR Distribution Chart of the network before and after Optimization.

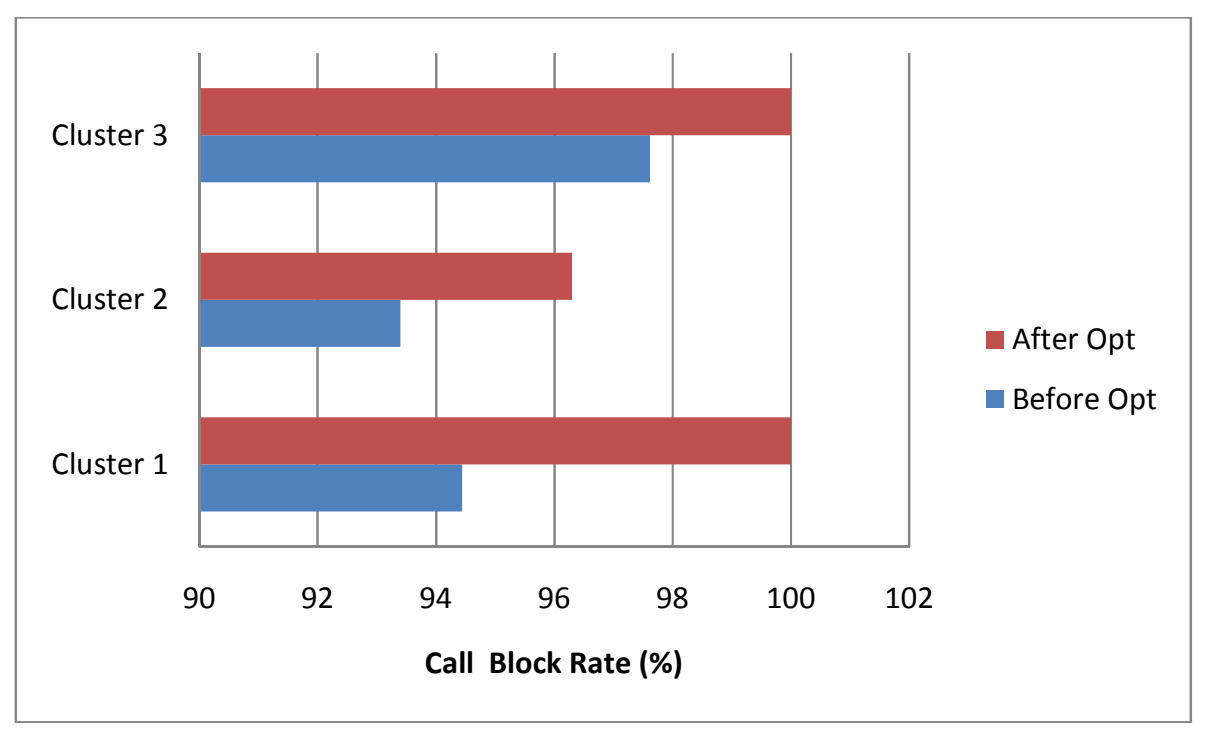


International Journal of Wireless \& Mobile Networks (IJWMN) Vol. 6, No. 5, October 2014

Figure 3: Call Blocking Rate Distribution Chart of the network before and after Optimization.

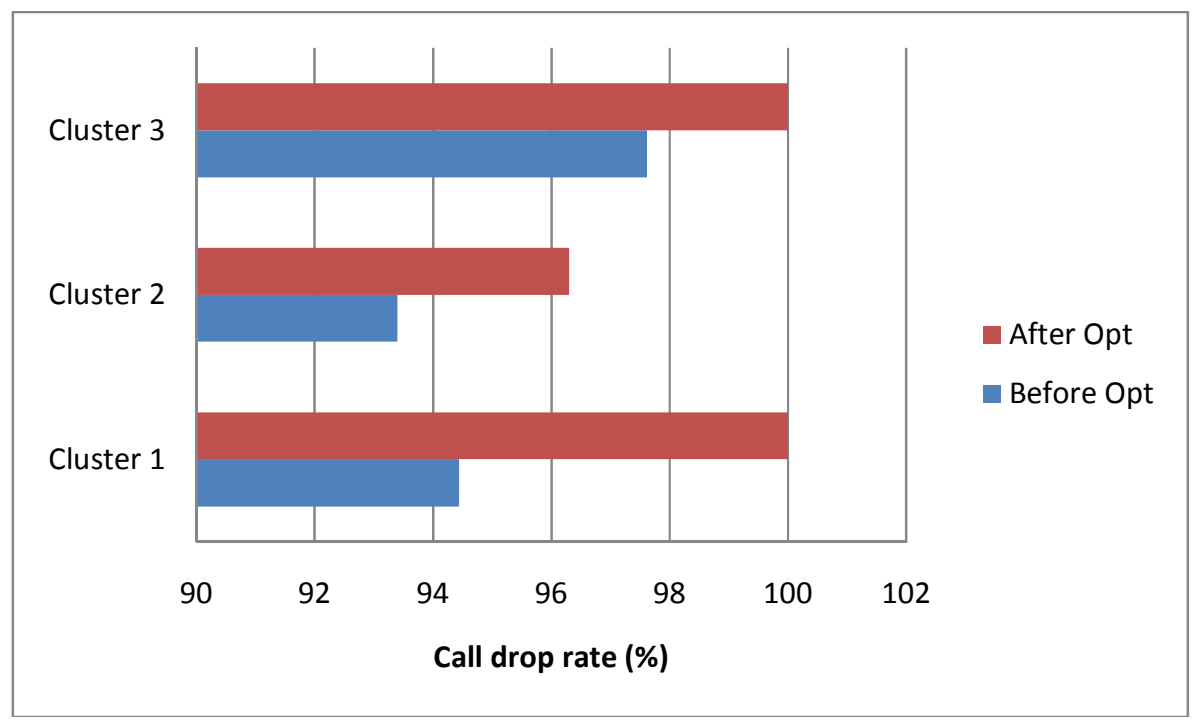

Figure 4: Call drop Rate Distribution Chart of the network before and after Optimization.

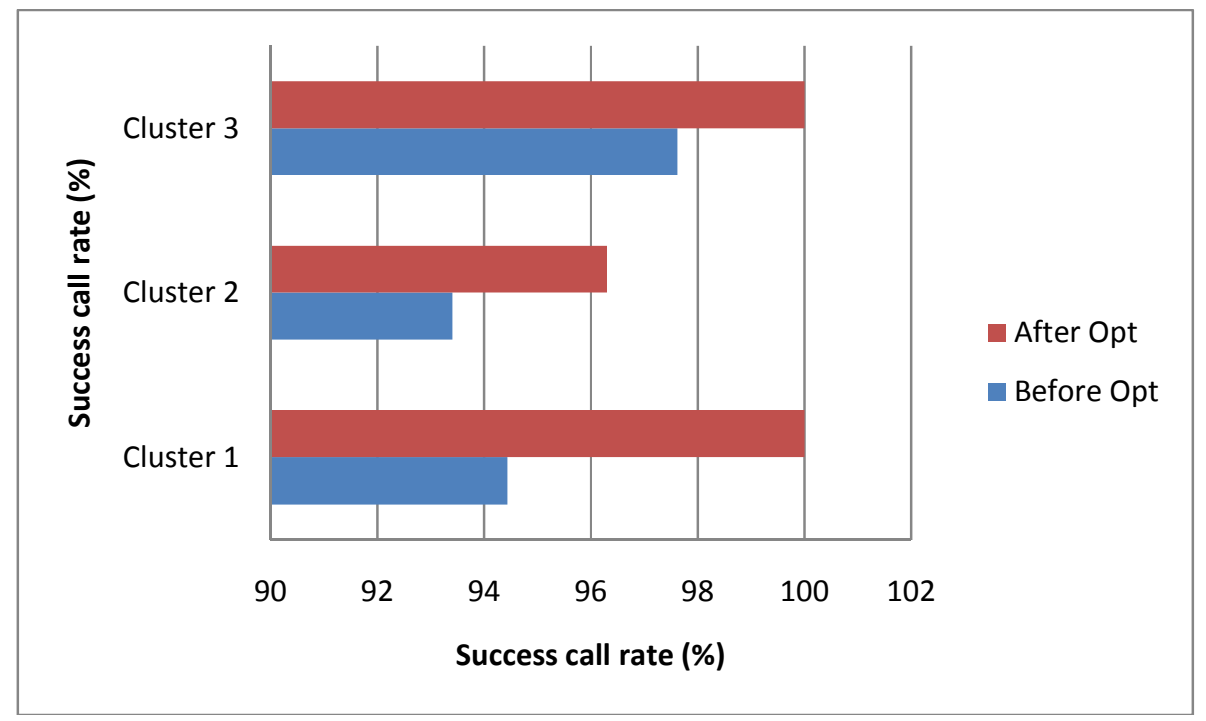

Figure 5: Call Success Rate Distribution Chart of the network before and after Optimization. 
International Journal of Wireless \& Mobile Networks (IJWMN) Vol. 6, No. 5, October 2014

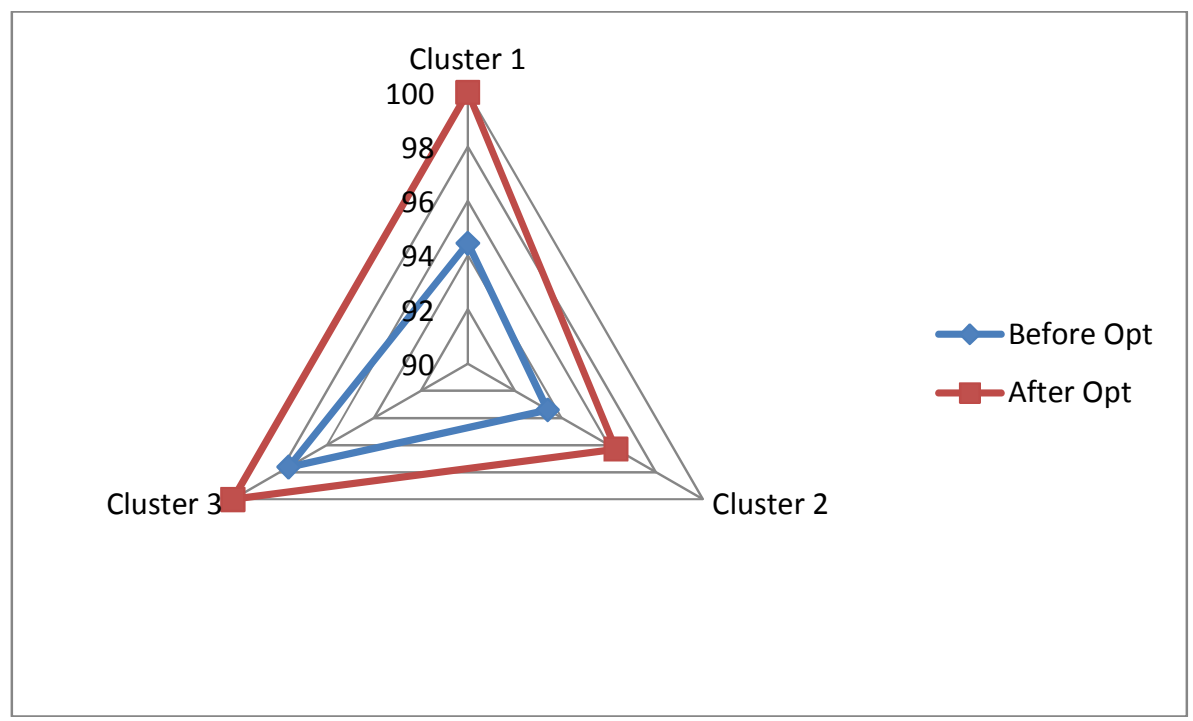

Figure 6 (a) Radar plot of end user SATR as a function of the cell clusters

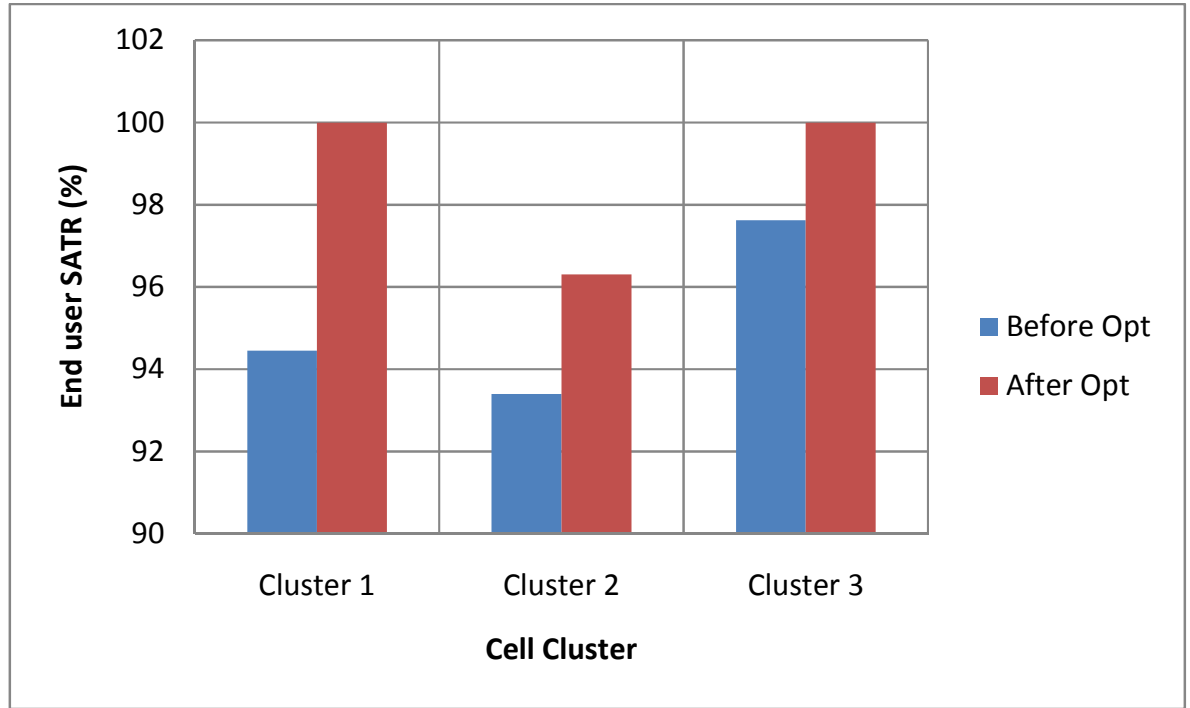

Figure 6 (b) Bar chart plot of end user SATR as a function of the cell clusters 
International Journal of Wireless \& Mobile Networks (IJWMN) Vol. 6, No. 5, October 2014

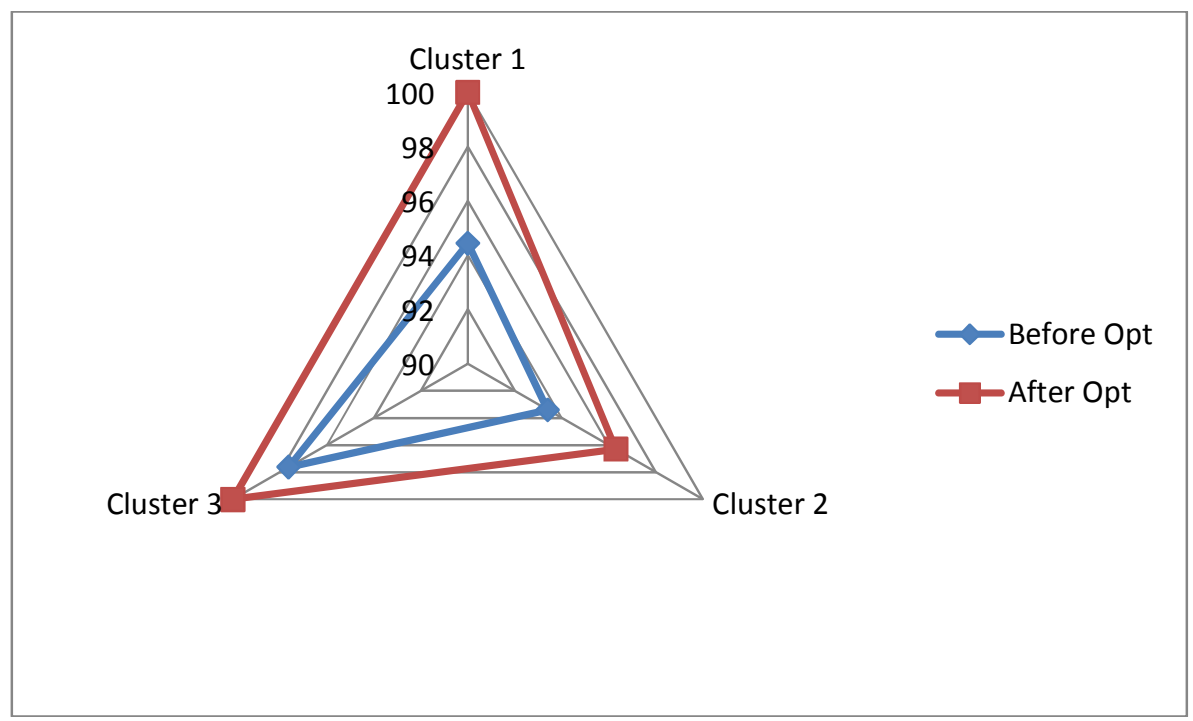

Figure 7 (a) Radar plot of ESA as a function of the cell clusters

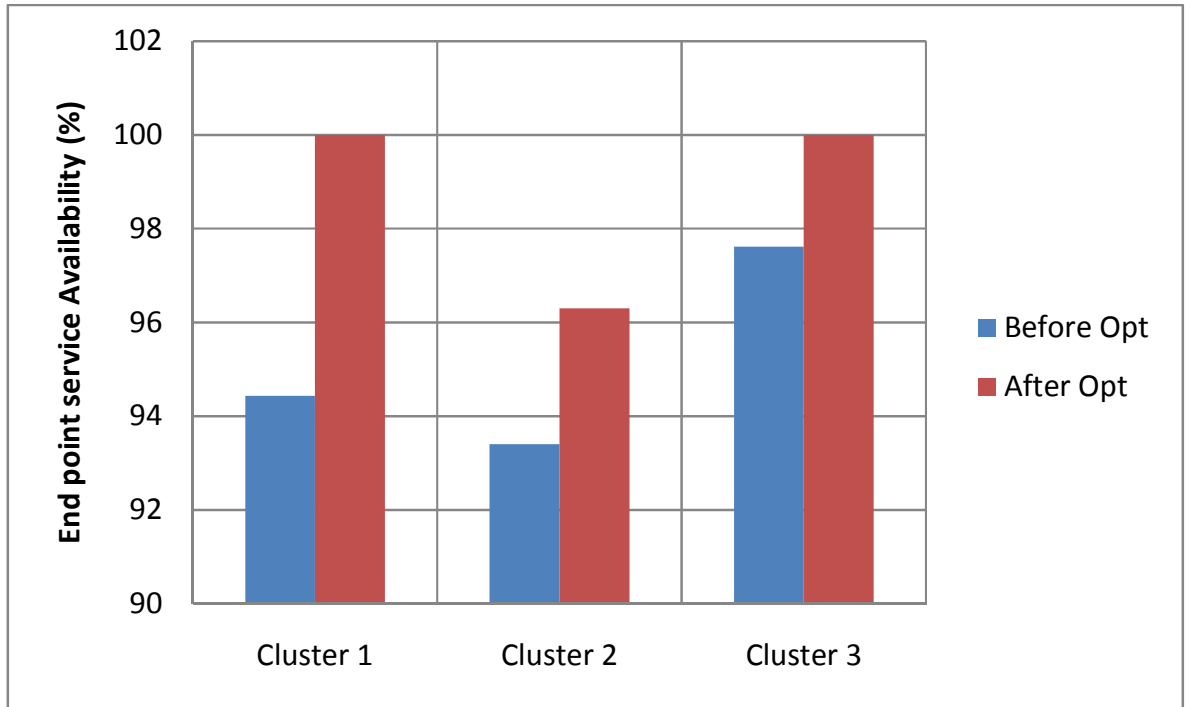

Figure 7 (b) Bar chart plot of ESA as a function of the cell clusters 
International Journal of Wireless \& Mobile Networks (IJWMN) Vol. 6, No. 5, October 2014

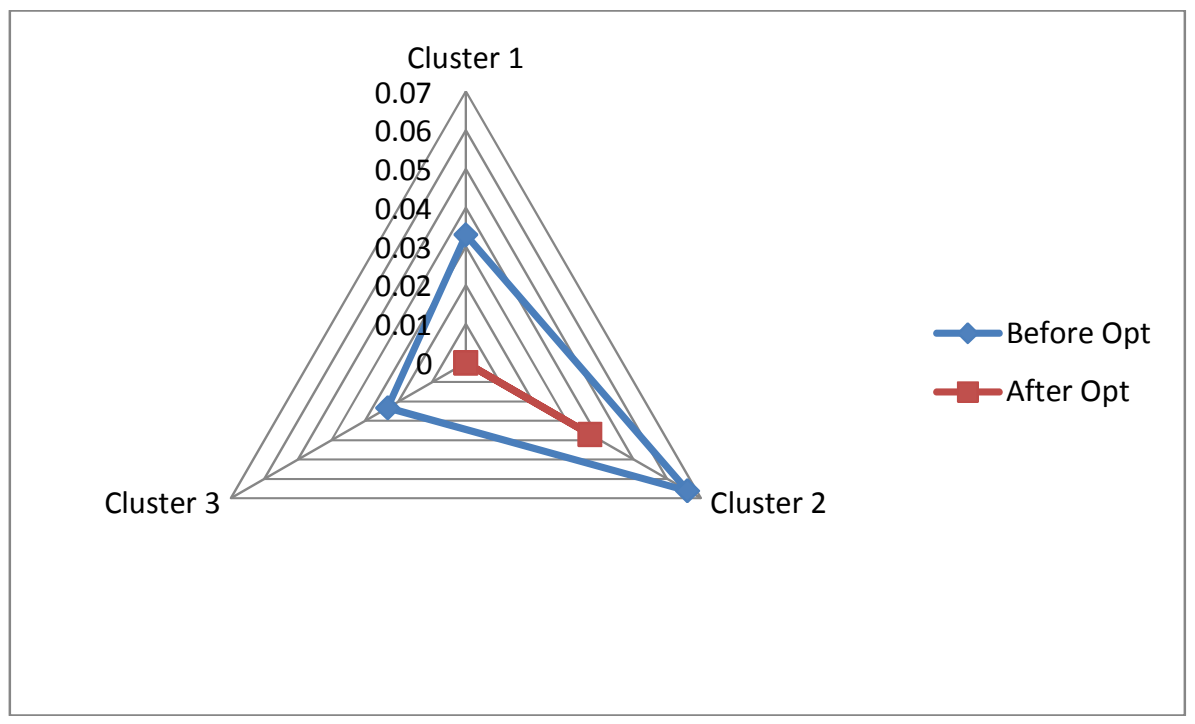

Figure 8: Radar plot of GoS as a function of the cell clusters

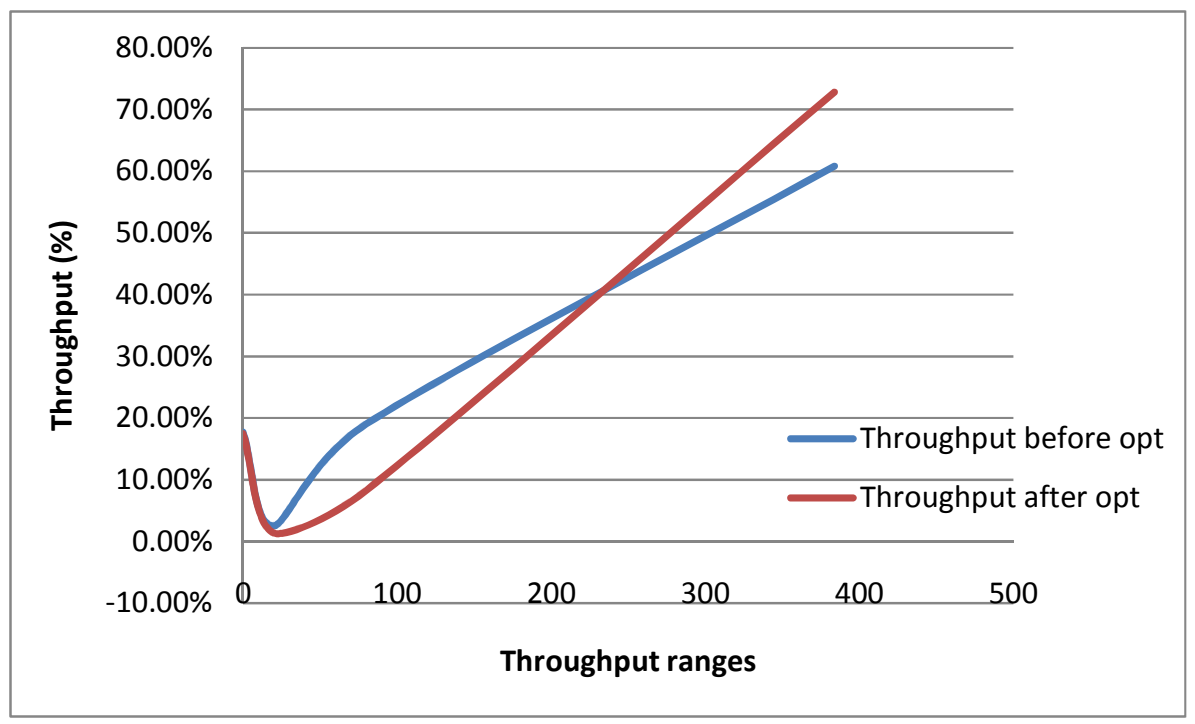

Figure 9: Average Throughput performance before and Optimization in cluster1 
International Journal of Wireless \& Mobile Networks (IJWMN) Vol. 6, No. 5, October 2014

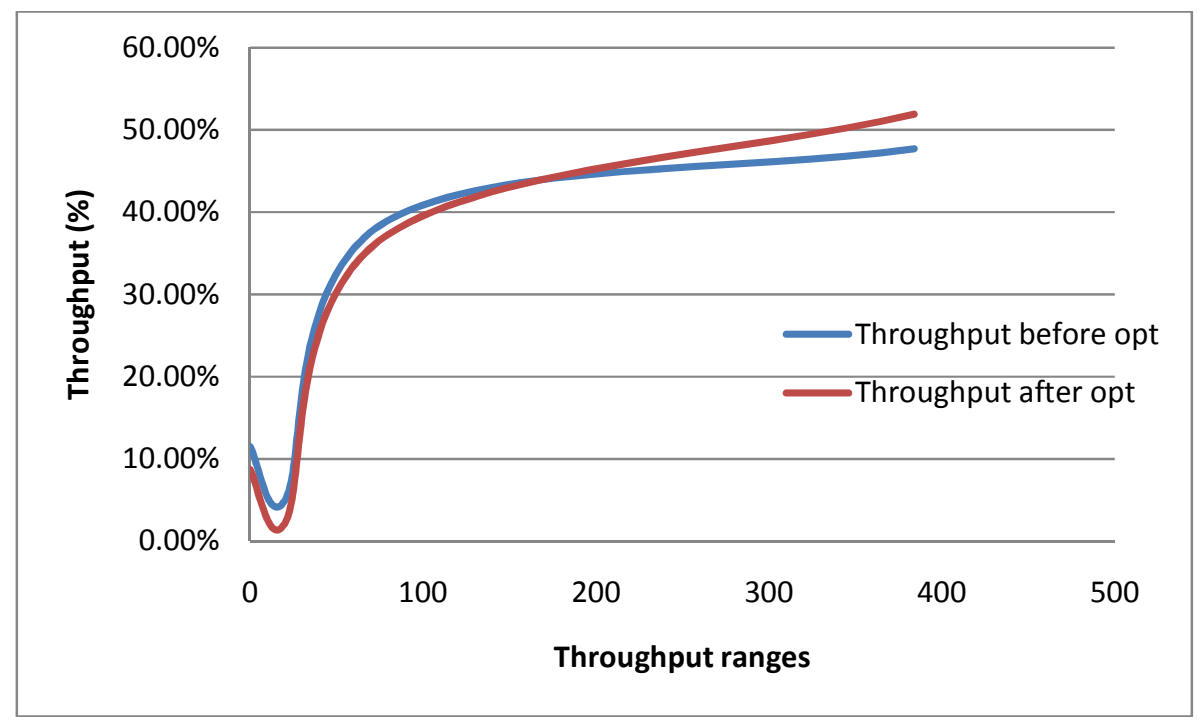

Figure 10: Average Throughput performance before and Optimization in cluster2

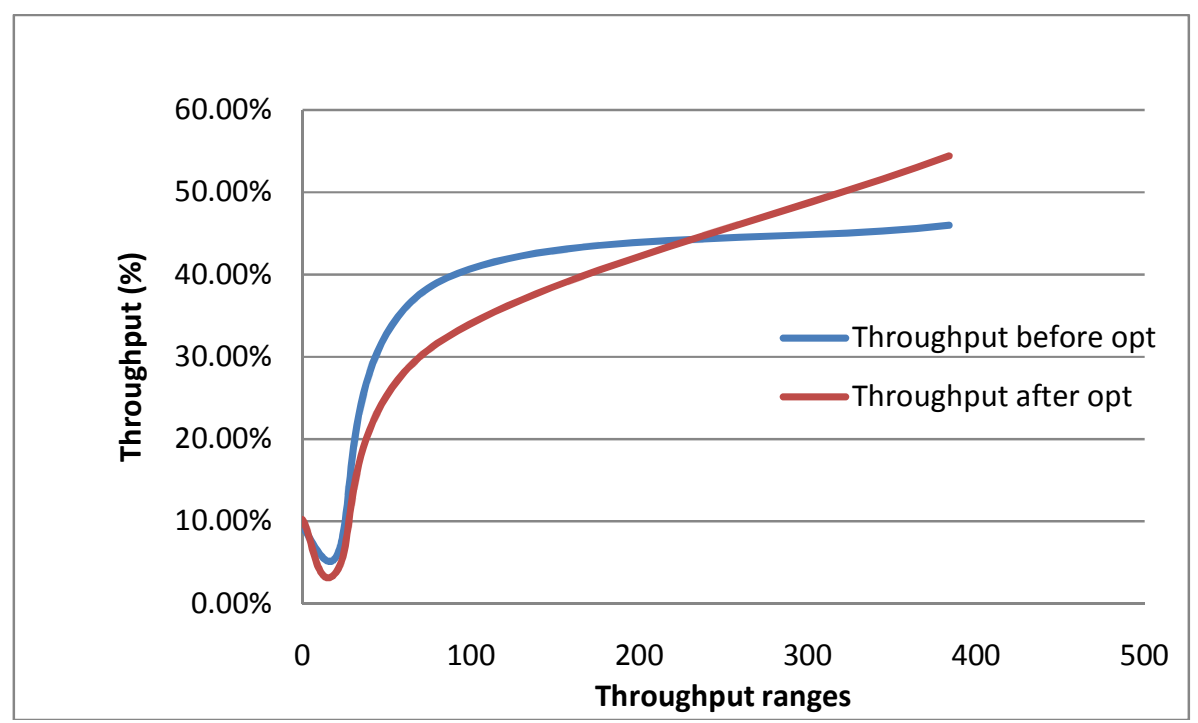

Figure 11: Average Throughput performance before and Optimization in cluster3

\section{CONCLUSION}

Mobile communications has become an indispensible element of modern lifestyle. The wide adoption of smart phones and other mobile devices such as smart tablets and e-readers has spurred rapid growth in wireless mobile communication. In order to meet user performance expectations and enhance user experiences, effectively managing the wireless mobile communication networks is imperative. In this paper, we presented an empirical case study on the focus of the performance evaluation and optimisation of GSM mobile network in Asaba Region, Nigeria. We specifically employ a combination of essential KPIS such as dropped call rate, call setup success rate and outage call rate to examine overall QoS and GoS performance of the 
investigated GSM network. Our results after network optimisation showed significant performance improvement in terms of call drop rate, call set up success rate, and call block rate across. Specifically, the end user satisfaction rate has increased from $94.45 \%, 87.74 \%$, and $92.85 \%$ to $99.05 \%, 95.38 \%$ and $99.03 \%$ respectively across the three GSM cell clusters. The GoS is reduced from $3.33 \%, 6.60 \%$ and $2.38 \%$ to $0.00 \%, 3.70 \%$ and $0.00 \%$ respectively. Furthermore, ESA, which correspond end points service availability, has improved from $94.44 \%, 93.40 \%$ and $97.62 \%$ to $100 \%, 96.30 \%$ and $100 \%$ respectively. In addition, the average throughput has improved from $73.74 \mathrm{kbits} / \mathrm{s}, 85.06 \mathrm{kbits} / \mathrm{s}$ and $87.54 \mathrm{kbits} / \mathrm{s}$ to $77.07 \mathrm{kbits} / \mathrm{s}, 92.38 \mathrm{kbits} / \mathrm{s}$ and $102 \mathrm{kbits} / \mathrm{s}$ respectively across the three GSM cell clusters.

\section{REFERENCES}

[1] 3GPP. Functionality in early GSM releases, 2009. http://www.3gpp.org, [Online; accessed 21-June2014].

[2] Wikipedia, "Global System for Mobile communications”, http://en.wikipedia.org/wiki/GSM

[3] Isabona, J and Peter I. G. Benchmarking Mobile Network Quality of Service with Essential Key Performance Indicators: A Case Study of Operational GSM Telecom Operators in Nigeria. Conference Proceedings of Nigerian Institute of Physics, 2014.

[4] Jang-Sub, K., Erchin, S., Dong-Ryeol, S., and Khalid, Q., Handoff Triggering and Network Selection Algorithms for Load-Balancing Handoff in CDMA-WLAN Integrated, 2008.

Networks, EURASIP Journal on Wireless Communications and Networking, vol. 2008, pp 1-14.

[5] ITU-T Rec. E.800, "Terms and Definitions Related to Quality of Service and Network Performance Including Dependability," Aug. 1993.

[6] ETSI TS 102 250-1, "Speech Processing, Transmission and Quality Aspects (STQ); QoS aspects for popular services in GSM and 3G networks; Part 1: Identification of Quality of Service aspects", V1.2.1, Technical Specification, 2007.

[7] Gambetti, I.C (2007). Wireless Heterogeneous Networks, Ph.D Thesis (Unpublished), University of Bologna, Alberto Zanella.

[8] Moner, J, Syed, A.H and Adel, R (2002) Modified Stochastic Knapsack for UMTS Capacity Analysis, Fujitsu Science Technical Journal, 38, 2 pp 183-191.

[9] Dajab D.D., Tarka S.N., Bajoga B.G., "Simulation and Analysis of Drop-call Probability Model: A case Study of MTEL”, Nigerian Journal of Engineering, Vol. 16, No.1, 2009.

[10] Tarka S. Nathaniel, "Effects of Network characteristics on Conditional Drop Probability: A case Study of MTEL", MSc Thesis, Department of Electrical Engineering, Ahmadu Bello University, Zaria, 2009.

\section{OUR PROFILE}

Dr. Kingsley Obahiagbon is a Head of Department and a lecturer in the Department of Mathematics and Computer Science, Benson Idahosa University, Benin City, Nigeria. He received PhD degree in Informatics, 1988 from Milan State University (Italy) and B.Sc. in Mechanical Engineering in 1983, from Carpi Institute of Technology, Italy. He has tau ght in various Higher and Post Primary Institutions both in United Kingdom and Italy. He is a member of various professional bodies in United Kingdom, which includes: Member of

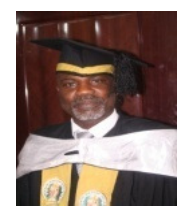
British Computer Society (MBCS), Member of British Engineering Council (CEng), Chartered Institute of Information Scientist (CITP) General Teaching Council for England. He has published nationally and internationally. His research interests are in Computer Modelling, Simulation, Computer Network and Communications. 
Dr. Joseph Isabona is a Senior lecturer in the department of Basic Sciences (Physics Unit), Benson Idahosa University, Benin City, Nigeria. He received Ph.D and M.Sc. degrees in Physics Electronics, 2013 and 2007 from the University of Benin and Uyo respectively, and a B.Sc in Physics in 2003, from Ambrose Alli University, Ekpoma, Edo State. He is a member of the Nigerian Association of Mathematical Physics (NAMP) and Nigeria Institute of Physics. He has published both nationally and internationally in the area of wireless communications. His area of interest is signal processing and radio resource management in wireless networks. My mails are: jisabona@biu.edu.ng 